\title{
HOW TEMPERAMENT, CHARACTER, FLOW STATE \& MOTIVATION PLAY ROLE IN ADVENTURE \& NON-ADVENTURE SPORTS: A COMPARATIVE STUDY
}

\author{
Debjani Kar ${ }^{1 i}$, \\ Prasanta Kumar Roy ${ }^{2}$ \\ ${ }^{1}$ Assistant Professor, \\ Department of Clinical Psychology, \\ Central Institute of Psychiatry, \\ Ranchi, Jharkhand 834006, \\ India \\ ${ }^{2}$ Associate Professor \& HOD, \\ Department of Clinical Psychology, \\ Institute of Psychiatry, Kolkata 700025,
}

India

\begin{abstract}
:
Adventure Sports (AS) is mostly associated with high risk-taking behaviors, unlike Nonadventure sports (NAS). Still, the AS persons can be highly functional while risking their lives for their passion for adventure sports. Therefore, we assumed for this study that the psychological processes involved in participation in Adventure sports might be different. The study intended to identify the difference in dispositional factors, the experience of flow state and motivational factors of Adventure Sports persons as compared to Nonadventure Sportspersons. The sample consisted of trained persons/professionals of Adventure Sports (viz. mountaineering, kayaking, river rafting, etc.) (n = 21) and participants of Non-adventure outdoor sports (viz. cricketers, footballers, etc.) $(n=21)$. We used the Temperament and Character Inventory, Flow State Scale, and Motivational Factors Scale. The findings revealed that low harm avoidance could be a dispositional factor for choosing adventure sports whereas; to gain status could be a factor to select non-adventure games.
\end{abstract}

Keywords: adventure sport, disposition, flow state, motivation, risk-taking

\section{Introduction}

Adventure sports are typically presumed to have a risk-taking focus (Cater, 2006). The term extreme sports are considered to be a descriptor for a multitude of non-traditional,

i Correspondence: email debjaniwbsu@gmail.com 
independent, and organized alternative sports. Activities that require high-level training, personal skills, and commitment such as B.A.S.E. (building, antenna, span, and earth cliff) jumping, rope-free climbing, and waterfall kayaking are assumed to be in the same category of extreme sports. Extreme sports are different than those sports which require no participant skills or dedication and little prior knowledge of the activity such as commercial rafting, low-level trekking, bungee jumping, and single pitch climbing (Palmer, 2004; Wheaton, 2004). Studies have explored, all extreme sports have a similar set of preconceived notions of inherent danger (Baker \& Simon, 2002; Palmer, 2003; Robinson, 2004). Adventure Sports or extreme sports have growing in popularity over the past few decades despite involving a considerable amount of inherent risk of injuries \& even life (Mei-Dan O \& Carmont, 2012). Indeed, people die when hazards, mistakes, or accidents are not effectively managed (Cater, 2006; Palmer, 2003). In 1996, sixteen people died on Everest, eight in one day. In 1999, twenty people died on a canyoning trip in Switzerland, and seven people died in a canyoning disaster in 2008 (Watson, Calman, \& McDonald, 2008). In recent times also, even the skilled mountaineers \& "sherpas" have died during Everest \& other expeditions (13 sherpas have expired in Mt. Everest expedition, May 2014; Chanda Gayen \& two Sherpas were missing during Mt. Yang lung Tang expedition, June 2014). Such statistics indicate that participation in adventure sports involve certain peoples' desire to take "unnecessary risks" (Pollay, 2001; Puchan, 2004; Rinehart, 2005). Participation rates are increasing, while traditional sports seem to be struggling (Pain \& Pain, 2005).

Therefore, the question arises what psychological variables, if at all, are the determining features of the participants of adventure sports. According to Ewert (1989), risk creation is itself a recreational activity in which risk and danger are experienced in the natural environment, and an individual's abilities play an important role in considering the outcomes of the situation. However, Apter (1992) further argued extreme sports to be non-game like situations or a mere question of coincidence, rather a question of taking "calculated risk." Other views have explained participation in adventure sports as a function of sensation seeking (Rossi \& Cereatti, 1993; Zuckerman, 2000), pathology (Hunt, 1995), youth (Bennett, Henson, \& Zhang, 2003; Midol \& Broyer, 1995), masculinity (Pollay, 2001; Wheaton, 2003) and narcissism (Elmes \& Barry, 1999). However, there are controversies and arguments regarding such theories. Therefore, the exact nature of what constitutes an extreme sport is still unclear (Olivier, 2006).

However, research has indicated temperamental traits \& genetic heritability are associated with adventure sports (Monasterio, 2007). Previous studies (Monasterio et al. 2012, 2016) stated BASE jumpers have higher novelty seeking and lower harm avoidance which is consistent with the findings that adventure sports require participants to be less fearful than the average individuals. Also, adventure sports participants' lower reward dependence scores explained their below-average social attachment and sentimentality. Overall, those studies have indicated common traits such as high novelty seeking, low harm avoidance, high self-directedness, and high cooperativeness. Other studies have shown specific aspects of personality differ significantly in adventure sportspersons than 
in the normative populations. However, to describe what makes an experience genuinely satisfying, Csikszentmihalyi (1990) has described flow, a state of consciousness, in which one's concentration is so focused that it amounts to absolute absorption in an activity. Flow experiences consist of a feeling of being active, alert, in effortless control, unselfconscious, and at the peak of abilities. The sense of time lost, along with emotional problems. There is a feeling of transcendence during that particular activity. This pleasurable state can be induced, by setting challenges of those tasks that are neither too difficult nor too simple as per the abilities. With such goals, it can be learned to order the information that enters consciousness and thereby improve the quality of life.

Some of the most important causes, among numerous factors, behind choosing and continuing with a particular kind of sport are related to different domains of personality, such as sensation seeking, temperament (intrinsic factors) \& character (environmental factors). Besides, there may be intrinsic motivation or the experience (flow state) during the performance itself, along with other motivational factors for continuing in a sport, especially where risk factors are high (adventure sports). Furthermore, in a country like India, where adventure sports are mainly attempted mostly for amusement by the general public under a highly secured set up, there are very few practically try with non-professional or without any business motives. Moreover, adventure sports are very costly to participate in India as there is hardly any donation from the government, even private organizations as they do not find any financial benefit on their part. Therefore, the present study attempts to explore some of the most relevant aspects of personality (viz, temperament \& character, flow state, and motivational factors especially economic burden or social issues) in adventure sports compared to its nonadventure counterpart.

\section{Material and Methods}

\subsection{Operational Definition}

For the present study, we have defined Adventure Sports as non-conventional sports that inherently require high physical as well as psychological toughness for survival in a critical natural environment.

For the present study, Non-adventure Sports are conventional or traditional physical outdoor activities done in a group or solo, which do not involve any critical natural environment.

\subsection{Hypothesis}

We hypothesize for the current study that there would be no significant differences between the adventure and non-adventure sportspersons in terms of temperament \& character, flow state, and motivational factors. 


\subsection{Study Design}

The study was comparative and cross-sectional. The convenience sampling method was chosen for data collection.

\subsection{Sample}

Participants were selected from institutes of adventure sports, clubs, and adventure sports associations. For the Sports group, participants were selected mainly from employees of government offices employed in sports quota. Besides they were selected from sports associations and clubs.

\subsubsection{Inclusion Criteria}

The Adventure sports group was the study group which consisted of experienced/professionals in their respective adventure sports such as, alpine mountaineers (Newzealand grade 5 to 7), high altitude trekkers (experience of $5000 \mathrm{mt} \&$ above), Sports climbers, and ice-skiiers.

For Non-adventure sports, we included, footballers, cricketers, volleyball \& basketball players, swimmers, and other non-adventure sportspersons were in the study. The minimum educational qualification was of class $X$ for both the group. The participants gave written consents for the collection of data.

\subsubsection{Exclusion Criteria}

We exempted persons having any physical disability or any diagnosed psychiatric problems from the study.

\section{Procedure}

We received ethical clearance from the institutional ethical committee for this study. Each of the participants gave written consent for participation. We've also taken written or verbal permissions for data collection from the concerned clubs and offices. The sample consisted of sportspersons $(\mathrm{N}=42)$ (both male and female) who are classified into two groups, viz. Adventure sports $(n=21 ; M=19, F=2)$ and Non-adventure sports $(n=21 ; M=$ $15, \mathrm{~F}=6$ ) group. All the tests used in the study were a self-administering test. The instructions were on the test booklet.

We screened the data primarily based on socio-demographic details. Therefore, we took 29 data out of 30 of Adventure Sports group, and 25 data out of 30 in the Nonadventure Sports group for further screening. Among those, four datasheets of Adventure sports group were incomplete. We further screened the data based on GHQ scores. We accepted those data in which GHQ score was $\leq 15$ as per norm (Zulkefly \& Baharuddin, 2010). Finally, we got 21 data from each group for statistical analysis. 


\subsection{Tools}

\subsubsection{Semi-structured Socio-demographic Datasheet}

It consisted of Name, Age, Sex, Occupation, Education, Marital Status, Average Monthly Income, Area Staying at, Name of Adventure sports/ Non Adventure Sports related with, Age of starting the sports \& Particulars and experiences of the sports.

\subsubsection{General Health Questionnaire (GHQ-12) (Goldberg \& William, 1978)}

It is a 12 item valid and reliable screening tool in detecting distress. The sensitivity and specificity of this scale were about $81.3 \%$ and $75.3 \%$ respectively (Yusoff, Rahim \& Yaacob, 2009). The reliability and validity of the scale ranged from .83 to .95 (Goldberg, Gater, Sartorius, Ustun, Piccineli, Gureje, \& Rutter, 1997). The norm used for the cut off score was given by Zulkefly \& Baharuddin (2010).

\subsubsection{Temperament \& Character Inventory (TCI-125) (Cloninger, 1987)}

The Temperament and Character Inventory (TCI) is a battery of tests designed to assess differences between people in seven basic dimensions of temperament \& character. Temperament refers to automatic emotional responses to experience that is moderately heritable and stable throughout life; the four measured temperament dimensions are Novelty Seeking, harm Avoidance, Reward Dependence, and Persistence. In contrast, a character refers to self-concepts and individual differences in goals and values, which influence voluntary choices, intentions, and the meaning of what is experienced in life. Differences in character are moderately influenced by socio-cultural learning and mature in progressive steps throughout life. The three measured character dimensions are SelfDirectedness, Cooperativeness, and Self-Transcendence. Each of these aspects of personality interacts with one another to motivate adaptation to life experiences and influence susceptibility to emotional and behavioral disorders. This inventory consists of a total of 125 questions.

\subsubsection{Flow State Scale (Jackson \& Marsh, 1995)}

Flow State is characterized by the feeling of being strong, alert, in effortless control, unselfconscious, at the peak of abilities and sense of time with emotional problems seemed to disappear for that time, along with an exhilarating feeling of transcendence (Csikszentmihalyi, 1990). This scale consists of 36 items divided into 9 subscales, each representing a different dimension. It is a 5 point rating scale in which the participants rate the items from "strongly disagree" to "strongly agree". The alpha internal consistency estimates of all subscales range from 0.79 to 0.86 . Confirmatory factor analytic research has supported a model with nine first-order and one higher-order factor (Jackson \& Marsh, 1996). 


\subsubsection{Motivational Factor Scale for Adventure Sports (Saxena \& Dey, 2010)}

This scale consists of 15 items to assess the motivational factors for adventure sports. The reliability (Cronbach Alpha is more than 0.874) \& validity (KMO was more than 0.7 ) were high.

All the tests used in the study were self-administering test. The instructions were printed on the test booklet.

\section{Results}

We calculated the data using Statistical Package for Social Sciences, Windows version 15 (SPSS 15). First, we checked the obtained data for normal distribution using Levene's Test for homogeneity of variances. As the data was homogenous, we considered parametric statistics despite the total sample size of 21 in each group. Then the data were further analyzed to see whether the groups differed concerning their Sex, Occupation, Average monthly income, Area staying at, Marital status, and religious views. Therefore, we did the chi-square test as those variables were nominal/categorical. Then, Independent sample t-test was used to obtain differences of means between the two groups in Age, Education, GHQ Scores \& Age of Starting Sport as the variables were on a continuous scale. Independent sample t-test was used to obtain differences of means between the two groups in disposition (temperament and character), flow state, and motivational factor for sports.

We did further analysis using the General Linear Model to see the Effect Size and Observed Power of an outcome variable having significant mean differences between two groups.

For analysis, 0.05 level of significance $(p=0.05)$ was considered as critical level. The Adventure Sports and Non-adventure Sports groups could be matched with respect to their Sex, Education, Marital Status, Average Monthly Income, Area Staying at and GHQ scores. However, the groups differed significantly with respect to their Occupation (chi square value $=6.04, \mathrm{p}$ value $=0.014)$, Age $(\mathrm{t}$-value $=-2.39, \mathrm{p}$-value $=0.022)$, Education $(\mathrm{t}-\mathrm{value}=2.86, \mathrm{p}$-value $=0.007)$ and Age of starting the sports $(\mathrm{t}-\mathrm{value}=5.31, \mathrm{p}$-value $=$ 0.001).

As per Table 1, the two groups significantly differed for the domains of Harm Avoidance and Cooperativeness. We couldn't find any differences between the groups for the variables of Novelty Seeking, Reward Dependence, Persistence, Self-Directedness, and Self Transcendence.

As per Table 2, for all the variables of Flow State, the p-values were higher, considering the accepted p-value as 0.05 . Therefore, this study failed to detect any significant difference in any of the variables between the two groups.

As per Table 3, all of the other variables except "Spells Status" and "Requires Toughness" among all motivational factors as the p-values were higher considering the accepted p-value as 0.05 . Therefore, our study failed to detect any significant difference in any of the variables between the two groups. 
As per Table 4, the Harm Avoidance had 19\%, Cooperation had 20\%, and Status had $12 \%$, effect in the outcome, i.e., choice and continuing of a particular type of sport. For analysis, 0.05 level of significance $(p=0.05)$ was considered as critical level. The Adventure Sports and Non-adventure Sports groups could be matched with respect to their Sex, Education, Marital Status, Average Monthly Income, Area Staying at and GHQ scores. However, the groups differed significantly with respect to their Occupation (chi square value $=6.04, \mathrm{p}$ value $=0.014)$, Age $(\mathrm{t}$-value $=-2.39, \mathrm{p}$-value $=0.022)$, Education $(\mathrm{t}-$ value $=2.86, \mathrm{p}$-value $=0.007)$ and Age of starting the sports $(\mathrm{t}$-value $=5.31, \mathrm{p}$-value $=0.001)$.

\section{Discussion}

The present study intended to identify the difference in dispositional factors, the experience of flow state, and motivational factors of Adventure Sportspersons as compared to Non-adventure Sportspersons. The results revealed that there are some differences in dispositional factors and motivational factors which play as determinants in choice or continuation of Adventure Sports over Non-adventure Sports and vice-versa. However, there was no significant difference found on any domain of Flow State Scale for both groups. These findings lead to further implications which we would discuss below.

\subsection{The Difference in Dispositional Factors}

The findings (Table No. 1) suggested that Adventure sportspersons were less harm avoidant compared to their Non-adventure counterparts. A similar study (Han et al. 2006) also showed athletes scored higher on harm avoidance than non-athletes; though the present study did not include the non-sports group. However, this finding implicates that the Adventure sportspersons are more lively, vigorous, and energetic than Nonadventure sportsmen (Cloninger, Przybeck, Svrakic \& Wetzel, 1994). Though the theoretical perspective assumed that participation in adventure sports was about risktaking only (Breivik, 1996; Baker \& Simon, 2002; Robinson, 2004; Henry, Findley, \& Reilly, 2007; Laurendeau, 2008); the present study supports the assumption that the participants with low Harm Avoidance (Monasterio et al., 2012), remain very much aware of these risks. Also, they perceive the possibility of suffering as a necessary dimension of the experience (Willig, 2008). The study by Monasterio et al. (2016) also showed higher than average Novelty Seeking and lower than average Harm Avoidance and Reward Dependence in AS persons as those are the pattern of "adventurous" temperament. The current study also showed comparatively low harm avoidance in the AS group than the NAS group. As this study didn't include non-sports individuals; therefore, we cannot comment on whether any difference is present in novelty seeking and reward dependence between AS and non-sports persons or not.

The findings (Table 1) also suggested that Adventure sportspersons were more cooperative than the Non-adventure group. Therefore, the Adventure sportspersons are more empathetic, tolerant, compassionate, supportive, and fair; and give preference to 
others' works as well as their own. These characteristics of the AS group could be significant in team-work and social groups for harmonious and balanced relationships to flourish (Cloninger et al., 1994). In most cases, participation in Adventure sports requires group involvement to the extent of life \& death. Therefore, cooperativeness needs to be high among Adventure sportspersons. Though engagement and understanding among group members are required in group sports too, it is not to the extent as it is in Adventure Sports. This inherent requirement of understanding and engagement among group members might be a reason for higher cooperativeness among Adventure sportspersons than the other group. However, from this study, the conclusion could not be drawn whether high cooperativeness was the predictor of choice of adventure sports or an acquired character skill of the Adventure sports participants.

This study does not indicate any significant difference between the groups in the domains of Novelty Seeking, Reward Dependence, Persistence, Self-Directedness, and Self Transcendence. However, few studies have revealed high Novelty Seeking and low Persistence on athletes than non-athletes (Han et al., 2006) and high Sensation Seeking in Adventure sportspersons than Non-adventure sportspersons (Kettunen et al., 1999; Lafollie, 2007; Rhea \& Martin, 2010). In this study, as we did not include Nonsportspersons, and did not assess the participants on the Sensation Seeking scale; therefore, we could not verify previous findings.

\subsection{The Difference in Flow State}

This study (as per Table 2) does not reveal any significant difference between Adventure sports and Non-adventure sports groups in any domain of flow state experiences as well as the total flow state scores. Previous studies show that flow is a very integral part of any sports activity as the participants have clear goals, immediate feedback, and have a balance between challenges and skill level (Jackson \& Csíkszentmihályi, 1999). Also, a study states that qualitative differences are present in different types of adventure sports (Mackenzie, Hodge \& Boyes, 2011). However, in this study, flow experiences were not found to differ for the adventure and non-adventure groups. This result might indicate that flow experiences do not depend on the type of activity performed; rather, it depends on the level of involvement of the participant in that particular activity. The prefrontal activity slows down in the flow state. Thus, the sense of time, fear, and other complex cognitive functions get eliminated, and the brain produces a sense of reward through that activity (Kotler, 2014). Therefore, this kind of experience is neurobiologically similar for all individuals who experience flow while doing any action. Thus, the current study supports the findings as it shows no significant difference in flow experience between the two groups. Therefore, Flow experiences can be assumed to be similar for professionals of any sport during the event.

\subsection{The Difference in Motivational Factors}

The study further reveals the motivational factors of participants for choosing their corresponding sports differed in some domains (Table 3). The results of the present study 
show, the thrill was the primary motivating factor for choosing Adventure Sports, which supports the previous studies (Zuckerman, 1983; Lewis, 2010). On the other hand, status and toughness were the main motivating factors for choosing Non-adventure Sports. In our country, adventure sports are not as recognized as non-adventure sports like cricket, football, etc. Therefore, status could be a motivating factor for choosing a career in nonadventure sports in contrast to adventure sports.

\subsection{Recommendations}

The significant limitations of the study include the difference in the number of participants of male and female. As female participants in adventure sports are generally very less in number, we couldn't find enough participants for this study. This study could be more enriched if we could increase the sample size by including participants from all parts of India, representing different races and cultures.

The results could be more generalizable without an effect of age, education, and occupation. Moreover, the researchers should try to replicate this study, including the Non-sportspersons' group, to compare the results without the influence of any sport. This study lacks important aspects of Sensation Seeking and emotional attachment, which might differ in Adventure and Non-adventure sportspersons as per previous literature. This study does not explain how risk-taking behavior differs from pathological risktaking behaviors, needing clinical intervention. Therefore, future studies should be conducted to demonstrate the genetic vulnerability of any pathology with risk-taking behaviors.

\section{Conclusion}

In conclusion, we can say that Low Harm Avoidance and high Cooperativeness are significant dispositional and character factors, respectively, that differ in Adventure sportspersons concerning Non-adventure sportspersons. We could not find any significant difference in Flow State experience between Adventure sportspersons and Non-adventure sportspersons. To get status was found to be the primary motivating factor for participation in Non-adventure sports in this study.

\section{Acknowledgments}

This study was conducted in India by the people who actively participate and earn their living by participating in adventure sports or non-adventure sports. We would like to thank all our participants, government agencies of India and adventure sports enthusiasts all over India, especially Darjeeling \& Manali who directly or indirectly helped us in this work. Without their enthusiastic participation and support, this study couldn't be possible. 


\begin{abstract}
About the Authors
Debjani Kar, Assistant Professor, Dept. of Clinical Psychology, Central Institute of Psychiatry, Ranchi, Jharkhand 834006, India. Email: debjaniwbsu@gmail.com. Research interest areas are Sports Psychology, Cognitive Psychology \& Clinical Psychology.

Prasanta Kumar Roy, Associate Professor \& HOD, Dept. of Clinical Psychology, Institute of Psychiatry, Kolkata -700025, India. Email: prasanta.roy@gmail.com.
\end{abstract}

\title{
References
}

Allman, T. L., Mittelstaedt, R. D., Martin, B., \& Goldenberg, M. (2009). Exploring the Motivations of BASE Jumpers: Extreme Sports Enthusiasts. Journal of Sport $\mathcal{E}$ Tourism,14(4), 229-247. doi:10.1080/14775080903453740

Apter, M. J. (1992). The Dangerous Edge: The Psychology of Excitement. New York: The Free Press.

Baker, T., \& Simon, J. (2010). Embracing Risk The Changing Culture of Insurance and Responsibility. Chicago, IL: University of Chicago Press.

Brymer, E. (2009). The Extreme Sports Experience: A Research report. IFPRA World, March. 6-7.

Brymer, E. (2010). Risk taking in Extreme Sports: A phenomenological perspective. Annals of Leisure Research,13(1-2), 218-238. doi:10.1080/11745398.2010.9686845

Brymer, E., \& Gray, T. (2009). Dancing with nature: Rhythm and harmony in extreme sport participation. Journal of Adventure Education E Outdoor Learning,9(2), 135-149. doi:10.1080/14729670903116912

Brymer, E., \& Oades, L.G. (2009). Extreme sports: a positive transformation in courage and humility? as accessed from http://eprints.qut.edu.au/27004

Brymer, E., \& Schweitzer, R. (2013). The search for freedom in extreme sports: A phenomenological exploration. Psychology of Sport and Exercise,14(6), 865-873. doi:10.1016/j.psychsport.2013.07.004

Cater, C. I. (2006). Playing with risk? Participant perceptions of risk and management implications in adventure tourism. Tourism Management,27(2), 317-325. doi:10.1016/j.tourman.2004.10.005

Cloninger, C.R., Przybeck, T.R., Svrakic D.M., Wetzel, R. (1994). "The Temperament and Character Inventory (TCI): A Guide to its Development and Use," Washington University. Retrieved from : http://www.researchgate.net/publication/264329741.

Csikszentmihalyi, M. (1990). Flow: The Psychology of Optimal Experience.

Ewert, A. (1994). Playing the Edge: Motivation and Risk Taking in a High Altitude Wilderness like Environment and Behavior. Journal of Travel Research, 26/ 1, 3-24.

Goldberg, D. P. (1978). Manual of the General Health Questionnaire, NFER Publishing Company. 
Han, D. H., Kim, J. H., Lee, Y. S., Bae, S. J., Bae, S. J., Kim, H. J., Sim, M. Y., Sung, Y. H., and Lyoo, I. K. (2006). Influence of Temperament \& Anxiety on Athletic Performance, International Journal of Sport Science \& Medicine, 5 (3), 381-389.

Hetland, A. (2009). Feeling the extreme: An exploratory study of experienced emotions during extreme sport. University of Tromso, Norway.

Jackson, S., Marsh, H. (1996). Development and Validation of a Scale to Measure Optimal Experience: The Flow State Scale, Journal of Sport E Exercise Psychology, 18(3), 1785.

Kerr, J. H. (1997) \& Svebak (1989). Motivational Aspects of preference for and participation in risk sports. Personality and Individual Differences, 10, 797-800.

Kettunen, S., Saukko, M. (1999). Live or Die: Extreme-Athletes' Personality Structure and Functioning, Motives, and Flow Experience, Jyvaskyla University, Finland.

Konkel, L. (2009). Extreme Psychology, There may be more to high-risk sports than a "no fear" mantra. Scienceline: the shortest distance between you and science, a project of nyu's science, health, and environmental reporting program, as accessed from https://scienceline.org/2009/07/health-konkel-extreme-sports-risk-psychology/

Kotler, S. (2019, January 30). Your Brain Performs Better When It Slows Down, with

Steven Kotler. Retrieved December 04, 2020, from https://bigthink.com/thinktank/steven-kotler-flow-states

Laffollie, D. (2010). Detection of high-risk personalities in risky sports, Encephale, 33 (2), 135-141.

Mackenzie, S. H., Hodge, K., Boyes, M. (2011). Expanding the Flow Model in Adventure Activities: A Reversal Theory Perspective, Journal of Leisure Research, 43(4), 519-544.

Monasterio, E., Mei-Dan, O., Hackney, A. C., Lane, A. R., Zwir, I., Rozsa, S., et al. (2016). Stress reactivity and personality in extreme sports athletes: the psychobiology of BASE jumpers. Physiol. Behav. 167, 289-297. doi: 10.1016/j.physbeh.2016.09.025

Monasterio, E., Mulder, R., Frampton, C., and Mei-Dan, O. (2012). Personality Characteristics of BASE Jumpers, Journal of Applied Sport Psychology, 24(4,), 391400 .

Monasterio, E., Mulder, R., Frampton, C., and Mei-Dan, O. (2012). Personality characteristics of base jumpers. J. Appl. Sport Psychol.24, 391-400. doi: 10.1080/10413200.2012.666710

Monasterio, Erik \& Mei-Dan, Omer \& Hackney, Anthony \& Lane, Amy \& Zwir, Igor \& Rózsa, Sándor \& Cloninger, Robert. (2016). Stress reactivity and personality in extreme sports athletes: The psychobiology of BASE jumpers. Physiology $\mathcal{E}$ Behavior. 167. 10.1016/j.physbeh.2016.09.025.

Pedersen, D. M., and Manning, C. L. (2004). Attributions of Athletes on Collegiate Sports Teams, Pubmed.gov, 99 (3.1), 799-810.

Rhea, D. J., \& Martin, S. (2010). Personality Trait Differences of Traditional Sports Athletes, Bullriders, and other Alternative Sports Athletes. International Journal of Sports Science \& Coaching,5(1), 75-85. doi:10.1260/1747-9541.5.1.75 
Saxena, K. \& Dey, A. (2010). Treks'n Rapids: Identifying Motivational Factors for Adventure Sports, Journal of Economics and Business Administration, 2 (2), 172-178.

Shill, D. (2013). The Effects of Personality Traits upon the Long Term Involvement of Participants in an Adventure Sport. University of Chichester.

Wheaton, B. (2005). Understanding lifestyle sports: Consumption, identity, and difference. London: Routledge.

Zuckerman, M. (1983). Sensation seeking and sports. Personality and Individual Differences, 4(3), 285-292. http://dx.doi.org/10.1016/0191-8869(83)90150-2

Zulkefly, S. N., and Baharudin, R. (2010). Using the 12-item General Health Questionnaire (GHQ-12) to Assess the Psychological Health of Malaysian College Students, Global Journal of Health Science, DOI: 10.5539/gjhs.v2n1p73. 


\section{Appendix}

Table 1: Mean, SD, Student's t-test value and p-values of dispositional factors comprising of four temperaments and three character domains of

Adventure Sports and Non-adventure Sports Groups ( $\mathrm{N}=42)$

\begin{tabular}{|l|c|c|c|c|c|c|}
\hline \multirow{2}{*}{ Variables } & \multicolumn{2}{|c|}{$\begin{array}{c}\text { Adventure Sports } \\
\mathbf{( N = 2 1 )}\end{array}$} & \multicolumn{2}{c|}{$\begin{array}{c}\text { Non-adventure Sports } \\
\mathbf{( N = 2 1 )}\end{array}$} & \multirow{2}{*}{$\begin{array}{c}\text { t-value } \\
\text { (df=40) }\end{array}$} & p-value \\
\hline & Mean & SD & Mean & SD & \\
\hline Novelty Seeking & 9.71 & 1.98 & 10.48 & 2.62 & 1.06 & 0.294 \\
\hline Harm Avoidance & $\mathbf{3 . 5 2}$ & $\mathbf{3 . 1 1}$ & $\mathbf{6 . 5 7}$ & $\mathbf{3 . 2 6}$ & $\mathbf{3 . 1 0}$ & $\mathbf{0 . 0 0 4}$ \\
\hline Reward Dependence & 7.48 & 2.80 & 7.86 & 1.53 & 0.55 & 0.588 \\
\hline Persistence & 4.10 & 1.26 & 4.14 & 0.86 & 0.14 & 0.887 \\
\hline Self Directedness & 16.52 & 2.89 & 15.48 & 3.87 & 0.99 & 0.326 \\
\hline Cooperativeness & $\mathbf{1 8 . 9 0}$ & $\mathbf{2 . 5 9}$ & $\mathbf{1 6 . 5 2}$ & $\mathbf{2 . 3 4}$ & $\mathbf{3 . 1 3}$ & $\mathbf{0 . 0 0 3}$ \\
\hline Self Transcendence & 8.43 & 2.69 & 8.95 & 2.99 & 0.60 & 0.554 \\
\hline
\end{tabular}

Table 2: Mean, SD, Student's t-test value and p-values of nine domains and total score of flow state experiences of Adventure Sports and Non-adventure Sports Groups (N=42)

\begin{tabular}{|l|c|c|c|c|c|c|}
\hline Variables & \multicolumn{2}{|c|}{$\begin{array}{c}\text { Adventure Sports } \\
\text { (N=21) }\end{array}$} & \multicolumn{2}{c|}{$\begin{array}{c}\text { Non-adventure } \\
\text { Sports (N=21) }\end{array}$} & $\begin{array}{c}\text { t-value } \\
\text { (df= 40) }\end{array}$ & $\begin{array}{c}\text { p- } \\
\text { Value }\end{array}$ \\
\hline $\begin{array}{l}\text { Autotelic Experience } \\
\text { (ENJOY) }\end{array}$ & 16.67 & 2.29 & 17.00 & 1.79 & 0.53 & 0.602 \\
\hline $\begin{array}{l}\text { Clear Goals } \\
\text { (GOAL) }\end{array}$ & 16.33 & 2.60 & 15.86 & 2.58 & 0.60 & 0.554 \\
\hline $\begin{array}{l}\text { Challenge-Skill Balance } \\
\text { (CHAL) }\end{array}$ & 16.57 & 2.09 & 16.86 & 1.82 & 0.47 & 0.639 \\
\hline $\begin{array}{l}\text { Concentration on Task } \\
\text { (CONC) }\end{array}$ & 16.29 & 2.05 & 15.81 & 2.34 & 0.70 & 0.487 \\
\hline $\begin{array}{l}\text { The paradox of Control } \\
\text { (CONT) }\end{array}$ & 17.10 & 2.30 & 16.43 & 2.27 & 0.95 & 0.350 \\
\hline $\begin{array}{l}\text { Unambiguous Feedback } \\
\text { (FDBK) }\end{array}$ & 15.38 & 2.64 & 15.67 & 2.20 & 0.38 & 0.705 \\
\hline $\begin{array}{l}\text { Acton-awareness merging } \\
\text { (ACT) }\end{array}$ & 15.24 & 2.05 & 16.24 & 2.12 & 1.56 & 0.128 \\
\hline $\begin{array}{l}\text { Transformation of Time } \\
\text { (TRAN) }\end{array}$ & 12.43 & 3.16 & 12.48 & 3.47 & 0.05 & 0.963 \\
\hline $\begin{array}{l}\text { Loss of Self-consciousness } \\
\text { (LOSS) }\end{array}$ & 14.19 & 2.38 & 14.43 & 3.41 & 0.26 & 0.795 \\
\hline $\begin{array}{l}\text { Flow State Total } \\
\text { (FSSTOTAL) }\end{array}$ & 137.29 & 15.63 & 139.33 & 15.89 & 0.42 & 0.676 \\
\hline
\end{tabular}


Table 3: Mean, SD, Student's t-scores and p-values of Motivational Factors of sports of Adventure Sports and Non-adventure Sports Groups (N=42)

\begin{tabular}{|l|c|c|c|c|c|c|}
\hline \multirow{2}{*}{ Variables } & \multicolumn{2}{|c|}{$\begin{array}{c}\text { Adventure } \\
\text { Sports (N=21) }\end{array}$} & \multicolumn{2}{c|}{$\begin{array}{c}\text { Non-adventure } \\
\text { Sports (N=21) }\end{array}$} & \multirow{2}{*}{$\begin{array}{c}\text { t-value } \\
\text { (df=40) }\end{array}$} & \multirow{2}{*}{ p-value } \\
\cline { 1 - 3 } & Mean & SD & Mean & SD & & \\
\hline Provides thrill & 6.71 & 0.46 & 6.29 & 0.96 & 1.85 & 0.072 \\
\hline Requires zeal/energy & 6.10 & 1.64 & 6.24 & 0.94 & 0.35 & 0.731 \\
\hline Spells status & $\mathbf{3 . 1 4}$ & $\mathbf{1 . 8 8}$ & $\mathbf{4 . 6 2}$ & $\mathbf{2 . 2 5}$ & $\mathbf{2 . 3 1}$ & $\mathbf{0 . 0 2 6}$ \\
\hline Builds confidence & 6.62 & 0.81 & 6.52 & 0.81 & 0.38 & 0.705 \\
\hline $\begin{array}{l}\text { Helps in personality } \\
\text { development }\end{array}$ & 6.29 & 1.45 & 5.57 & 1.63 & 1.50 & \multirow{2}{*}{0.142} \\
\hline Instills self-belief & 6.29 & 1.06 & 6.05 & 1.24 & 0.67 & 0.507 \\
\hline Creates unique identity & 5.43 & 1.54 & 6.05 & 1.32 & 1.40 & 0.169 \\
\hline Is a stress buster & 5.52 & 1.89 & 5.33 & 2.01 & 0.32 & 0.753 \\
\hline Helps in goal-setting & 5.57 & 1.47 & 5.48 & 1.91 & 0.18 & 0.857 \\
\hline Is challenging & 6.71 & 0.65 & 6.86 & 0.36 & 0.89 & 0.380 \\
\hline Requires toughness & $\mathbf{5 . 4 3}$ & $\mathbf{1 . 2 9}$ & $\mathbf{6 . 2 4}$ & $\mathbf{1 . 3 8}$ & $\mathbf{1 . 9 7}$ & $\mathbf{0 . 0 5 6}$ \\
\hline Builds a sense of achievement & 6.19 & 0.88 & 6.24 & 1.04 & 0.16 & 0.873 \\
\hline Is a unique experience & 6.67 & 0.66 & 6.58 & 0.67 & 0.35 & 0.730 \\
\hline It is fun/adventure & 6.76 & 0.44 & 6.42 & 0.90 & 1.49 & 0.147 \\
\hline $\begin{array}{l}\text { Improved technology has } \\
\text { reduced risk }\end{array}$ & 6.24 & 1.58 & 5.67 & 1.88 & 0.94 & 0.357 \\
\hline
\end{tabular}

Table 4: Analysis by General Linear Model

\begin{tabular}{|l|c|c|c|c|}
\hline Variables & t-value & Significance & Partial Eta Squared & Observed Power \\
\hline Harm Avoidance & -3.10 & 0.004 & 0.19 & 0.86 \\
\hline Cooperation & 3.13 & 0.003 & 0.20 & 0.86 \\
\hline Spells Status & -2.31 & 0.03 & 0.12 & 0.62 \\
\hline
\end{tabular}


Debjani Kar, Prasanta Kumar Roy

HOW TEMPERAMENT, CHARACTER, FLOW STATE \& MOTIVATION PLAY

ROLE IN ADVENTURE \& NON-ADVENTURE SPORTS: A COMPARATIVE STUDY

Creative Commons licensing terms

Authors will retain the copyright of their published articles agreeing that a Creative Commons Attribution 4.0 International License (CC BY 4.0) terms will be applied to their work. Under the terms of this license, no permission is required from the author(s) or publisher for members of the community to copy, distribute, transmit or adapt the article content, providing a proper, prominent and unambiguous attribution to the authors in a manner that makes clear that the materials are being reused under permission of a Creative Commons License. Views, opinions and conclusions expressed in this research article are views, opinions and conclusions of the author(s). Open Access Publishing Group and European Journal of Physical Education and Sport Science shall not be responsible or answerable for any loss, damage or liability caused in relation to/arising out of conflict of interests, copyright violations and inappropriate or inaccurate use of any kind content related or integrated on the research work. All the published works are meeting the Open Access Publishing requirements and can be freely accessed, shared, modified, distributed and used in educational, commercial and non-commercial purposes under a Creative Commons attribution 4.0 International License (CC BY 4.0). 